Rev. Bras. Saúde Prod. Anim., Salvador, v.14, n.3, p.406-412 jul./set., 2013 http://www.rbspa.ufba.br ISSN 15199940

\title{
Respostas fisiológicas e produtivas de vacas holandesas em lactação submetidas ou não a sombreamento e aspersão na pré-ordenha
}

\author{
Physiological and productive responses of Holstein cows in fosterage submitted or not \\ to shading and aspersion in premilking
}

\author{
CERUTTI, Weiler Giacomazza ${ }^{1 *}$; BERMUDES, Rogério Fôlha ${ }^{1}$; VIÉGAS, Julio ${ }^{3}$; \\ MARTINS, Cristian Marlon de Magalhães Rodrigues ${ }^{4}$
}

\footnotetext{
${ }^{1}$ Universidade Federal de Santa Maria, Departamento de Zootecnia, Santa Maria, Rio Grande do Sul, Brasil.

${ }^{3}$ Universidade Federal de Santa Maria, Departamento de Zootecnia e Ciências Biológicas, Palmeira das Missões, Rio Grande do Sul, Brasil.

${ }^{4}$ Universidade de São Paulo, Faculdade de Medicina Veterinária e Zootecnia, Departamento de Nutrição e Produção Animal, Pirassununga, São Paulo, Brasil.

*Endereço para correspondência: weiler_cerutti@yahoo.com.br
}

\section{RESUMO}

Objetivou-se, avaliar a influência de alguns recursos de climatização na produção e composição do leite e nas variáveis fisiológicas, freqüência respiratória, freqüência cardíaca, temperatura retal. Foram utilizadas 14 vacas da raça Holandesa, em um experimento com delineamento inteiramente casualizado com dois tratamentos: sala de espera com sombreamento acrescido de aspersão (climatizado) e sala de espera sem estrutura de climatização (não climatizado), sendo sete vacas por tratamento. Os dados climáticos de cada tratamento foram registrados para calcular o Índice de Temperatura e Umidade. A produção de leite diária foi significativamente superior no tratamento climatizado frente ao não climatizado, 13,97 contra $11,24 \mathrm{~kg}$ de leite, respectivamente. Não houve diferença entre os tratamentos para os componentes do leite (proteína, extrato seco desengordurado, densidade e gordura). $\mathrm{O}$ índice de temperatura e umidade permaneceu dentro da zona de conforto térmico para vacas em lactação (72 a 78) no tratamento climatizado, porém o inverso ocorreu no tratamento não climatizado, 71,34 e 79,76, respectivamente. Os animais que não desfrutaram da climatização apresentaram aumento da temperatura retal, da freqüência respiratória e cardíaca, quando comparados aos animais do tratamento climatizado.

Palavras-chave: acondicionamento de ambiente, conforto térmico, estresse calórico, frequência cardíaca, frequência respiratória

\section{SUMMARY}

It was aimed, to evaluate the influence of some acclimatizated resources in production and composition of milk in physiological variables, respiratory rate, heart rate and rectal temperature. It was used 14 cows of Holstein breed, in an experiment with completely randomized design with two treatments: shading waiting room added with aspersion (conditioned) and waiting room without acclimatized structure (not conditioned), having seven cows per treatment. The climatic data of each treatment were registered to calculate the temperature and humidity index. The daily milk production was significantly superior in conditioned treatment opposite to not conditioned, 13,97 against $11,24 \mathrm{~kg}$ of milk, respectively. There was not difference among the treatment for milk components (protein, nonfat dry extract, density and fat). The temperature and humidity index remained inside the thermal comfort zone for cows during fosterage (72-78) in conditioned treatment, however the inverse have happened in not conditioned treatment, 71,34 and 79,76, respectively. The animals that did not have acclimatization had presented an increase of rectal temperature, respiratory rate and heart rate, when compared to those animals in conditioned treatment.

Keywords: environment stowage, heart rate, heat stress, respiratory rate, thermal comfort 


\section{INTRODUÇ̃̃O}

Animais da raça Holandesa requerem temperaturas ambiente entre 5 e $18^{\circ} \mathrm{C}$ para a máxima expressão de seu potencial genético. Porém, valores acima desta faixa são facilmente verificados na maioria das regiões do Brasil, durante boa parte do ano. Isto ocorre principalmente nas regiões de baixa latitude, caracterizadas por elevados níveis de radiação solar e altas temperaturas (DIKMEN \& HANSEN, 2009).

Como resposta ao estresse térmico, mecanismos de termólise são acionados pelo metabolismo animal, e para manter a homeotermia interna, processos de desenvolvimento, produção e reprodução dos animais são prejudicados (AVENDANO et al., 2006). Os efeitos do estresse térmico são mais acentuados em animais com alta taxa metabólica, como vacas em lactação, e seus efeitos devem ser minimizados a partir de construções adequadas para abrigá-las (WEST, 2003; MARTELLO et al., 2004).

Medidas de alto custo para mitigar os efeitos do estresse térmico podem inviabilizar seu uso, principalmente quando $\mathrm{o}$ número de animais em produção não é suficiente para diluir em curto prazo os custos fixos da tecnologia adotada, e os ganhos em produção não são elevados de modo a compensar o investimento. Desta forma, medidas simples e eficazes devem ser adotadas em momentos e locais onde o estresse térmico pode ser mais impactante na produção de leite, tais como nas horas mais quentes do dia e/ou momentos antes da ordenha.

Até um limite máximo de $70 \%$ de umidade relativa do ar, a maneira mais eficiente de se resfriar um ambiente destinado a vacas em lactação, é fazer uso da água, uma vez que a mesma possui alta capacidade calorífica e elevado calor latente de vaporização. A dissipação de calor por meios evaporativos pode ser facilitada com a aplicação de água na superfície corporal do animal. A água evapora e remove o calor, favorecendo as trocas entre a pele e o ambiente. (NÄÄS \& ARCARO, 2001).

Diante destes problemas, alternativas como investir em climatização, adotando como uma das estratégias o uso da água na pré-ordenha, pode ser uma opção viável para manter os parâmetros fisiológicos de vacas em lactação próximos a homeostasia em períodos de temperaturas elevadas, e resultar em ganhos produtivos na lactação. Nesse contexto, o objetivo foi avaliar o efeito do sombreamento e da aspersão na pré-ordenha sobre as variáveis fisiológicas e desempenho produtivo de vacas em lactação da raça Holandesa.

\section{MATERIAL E MÉTODOS}

O estudo foi conduzido em uma propriedade comercial, localizada no município de Palmeira das Missões Rio Grande do Sul. O clima da região, segundo a classificação de Köppen, é do tipo Cfa - subtropical.

O experimento teve duração de 100 dias, durante a estação de verão, compreendendo os meses de janeiro a março de 2008. A seleção dos animais para o experimento contou com 14 vacas multíparas em lactação, da raça Holandesa, com peso corporal médio de $550 \mathrm{~kg}$ e produção média de leite de $12 \mathrm{~kg} /$ dia. As vacas foram divididas ao acaso em 2 tratamentos: "climatizado" e "sem climatização" (Tabela 1). 
Rev. Bras. Saúde Prod. Anim., Salvador, v.14, n.3, p.406-412 jul./set., 2013 http://www.rbspa.ufba.br ISSN 15199940

Tabela 1. Custo da instalação com sombreamento e aspersão

\begin{tabular}{lccc}
\hline Descrição & Quantidade & $\begin{array}{c}\text { Valor unitário } \\
(\mathrm{R} \$ / \text { metro) }\end{array}$ & Valor total (R\$) \\
\hline Mangueira microperfurada & 12 metros & 0,85 & 10,20 \\
Sombrite & $50 \mathrm{~m}^{2}$ & 0,90 & 45,00 \\
Tubulação polietileno & 30 metros & 0,45 & 13,50 \\
\hline Total (R\$) & - & - & 68,70 \\
\hline
\end{tabular}

Os tratamentos utilizados consistiram na permanência (climatizado) ou não (sem climatização) das vacas em uma instalação com sombreamento e aspersão na pré-ordenha. $\mathrm{O}$ pastejo, sistema voisin, era realizado em piquetes de tfton-85, distantes aproximadamente 100 metros das instalações (sala de ordenha e ambiente climatizado). De modo que, quando as vacas eram trazidas dos piquetes sete eram diretamente conduzidas a sala de ordenha para serem ordenhadas, e as outras 7, permaneciam por um período de 30 minutos em uma instalação provida de sombra e aspersão. Na sala de alimentação, logo após as ordenhas, que eram realizadas às 6 e as 18 horas, os animais recebiam suplementação individual com silagem de milho e concentrado a base de milho moído, farelo de soja e suplemento mineral.

A instalação, distante 10 metros da sala de ordenha e posicionada no sentido leste-oeste, apresentava dimensões de 3,5 metros de pé direito, $7 \mathrm{~m}$ de largura por $6 \mathrm{~m}$ de comprimento, totalizando uma área de $42 \mathrm{~m}^{2}\left(6 \mathrm{~m}^{2}\right.$ por vaca). Para a cobertura foi utilizada tela de fibra sintética (sombrite) com malha de 80\% de capacidade de bloqueio da radiação solar. A aspersão contou com duas linhas de mangueira microperfuradas a laser com espaçamento de $15 \mathrm{~cm}$ por pares de emissores, fixados na parte superior da instalação. Esse sistema era acionado manualmente e permanecia ligado ininterruptamente durante a permanência dos animais nesse ambiente.

Para a obtenção das temperaturas do bulbo seco (TBs), foram utilizados termômetros de coluna de mercúrio, com escala de -30 a $+50{ }^{\circ} \mathrm{C}$ e sensibilidade de $1^{\circ} \mathrm{C}$. Já a umidade relativa do ar foi registrada com auxilio de um termohigrometro digital. Com vista à eficiência térmica do tratamento climatizado, determinou-se o índice de temperatura e umidade (ITU), onde: $\mathrm{ITU}=0,8 \mathrm{Tbs}+\mathrm{UR}(\mathrm{Tbs}-14,3) / 100+$ 46,3 em que: ITU = índice de temperatura e umidade, adimensional; Tbs = temperatura de bulbo seco, em ${ }^{\circ} \mathrm{C}$; UR = umidade relativa do ar, em \% (BUFFINGTON et al., 1982).

Os parâmetros fisiológicos, freqüência respiratória $\left(\mathrm{FR} ; \mathrm{mov} . / \mathrm{min}^{1}\right)$, freqüência cardíaca (FC; bat./min.) e temperatura retal (TR; ${ }^{\circ} \mathrm{C}$ ), foram registrados nos dois turnos de ordenha, das 5 h $30 \mathrm{~min}$ às $7 \mathrm{~h}$ e das 18 às $20 \mathrm{~h}$, em ambos os tratamentos. A FR foi medida por contagem dos movimentos na região do flanco durante 60 segundos. A FC foi avaliada pela auscultação dos batimentos cardíacos na cavidade torácica do animal com o auxílio de um estetoscópio. E por fim, a TR foi avaliada com o auxílio de um termômetro de mercúrio, sendo que este permanecia por três minutos no reto das vacas.

A produção de leite diária (PLD) foi quantificada individualmente para cada animal em seu respectivo tratamento, para as duas ordenhas diárias (manhã e 
Rev. Bras. Saúde Prod. Anim., Salvador, v.14, n.3, p.406-412 jul./set., 2013 http://www.rbspa.ufba.br ISSN 15199940

tarde). Semanalmente, uma alíquota de leite, de cada animal, foi coletada para posterior análise de composição: Proteína, extrato seco desengordurado, densidade e gordura por método de radiação infravermelha (AOAC, 1995).

Para a obtenção do custo referente ao investimento, considerou-se apenas a aquisição dos equipamentos de climatização do ambiente (sombrite e mangueiras microperfuradas a laser), uma vez que os demais componentes já eram existentes na fazenda (mourões de madeira).

$\mathrm{O}$ delineamento experimental adotado foi o inteiramente casualizado, com dois tratamentos (climatizado e não climatizado) e sete repetições. Após verificar a normalidade dos resíduos e a homogeneidade das variâncias, os dados foram submetidos à análise de variância $(\alpha=0,05)$ pelo PROC ANOVA, utilizando-se o programa SAS versão 8.0 (SAS Institute, 2001).

\section{RESULTADOS E DISCUSSÃO}

As vacas submetidas ao tratamento climatizado obtiveram média de produção de leite $12,4 \%$ superior $(\mathrm{P}=$ 0,012 ) ao tratamento sem climatização (Tabela 2). Este resultado indica que medidas simples e de baixo custo, como sombreamento e aspersão, podem ser consideradas boas estratégias para mitigar os efeitos do estresse térmico momentos antes da ordenha e obter ganhos produtivos.

Tabela 2. Valores médios e erro padrão da média dos constituintes do leite avaliados nos diferentes tratamentos

\begin{tabular}{lccccc}
\hline \multirow{2}{*}{ Tratamentos } & \multicolumn{5}{c}{ Parâmetros } \\
\cline { 2 - 6 } & PLD $^{1}$ & Proteína & ESD $^{2}$ & Densidade & Gordura \\
\hline Climatizado & $13,97(1,24)$ & $3,28(0,14)$ & $9,02(0,16)$ & $31,87(0,49)$ & $2,12(0,13)$ \\
Não climatizado & $11,24(1,13)$ & $3,38(0,14)$ & $9,41(0,16)$ & $33,65(0,49)$ & $2,9(0,13)$ \\
CV (\%) & 30,3 & 9,4 & 8,9 & 12,7 & 24,3 \\
P & 0,012 & 0,350 & 0,182 & 0,208 & 0,194 \\
\hline
\end{tabular}

${ }^{1}$ Produção de leite diária; ${ }^{2}$ Extrato seco desengordurado.

O aumento da temperatura do ambiente resulta em aquecimento superficial e endógeno das vacas lactantes, e mudanças fisiológicas e metabólicas ocorrem nestes animais como tentativa de manter a homeostasia do metabolismo. Com o aumento da temperatura interna dos animais, através de estímulos nervosos a atividade tireoideana é reduzida, e os níveis de cortisol sérico são elevados, resultando em uma situação de estresse para os animais (SOUZA \& BATISTA, 2012). O estresse calórico é caracterizado pelo aumento da temperatura superficial e retal dos animais, e mecanismos de termorregulação, controlados pelo sistema endócrino e nervoso, são desencadeados, tendo como respostas principais $\mathrm{o}$ aumento das frequências respiratória e cardíaca (ARCARO JUNIOR et al., 2003; MARTELLO et al., 2004). Adicionalmente, em condições de temperaturas elevadas, os animais diminuem o consumo de alimentos como uma tentativa de reduzir a produção de calor endógeno gerado pelo incremento calórico durante os processos digestivos. Estas respostas comportamentais e metabólicas resultam em menor aporte de nutrientes para a glândula mamária, e 
consequentemente, a produção de leite é reduzida em condições de temperaturas acima do conforto térmico para vacas lactantes (BARBOSA et al., 2004).

Portanto, o uso de ventilação e aspersão pode ser eficiente para reduzir os efeitos negativos das altas temperaturas de ambiente sobre vacas em lactação. Adicionalmente, a estratégia de climatização com sombreamento e aspersão foi adotada na pré-ordenha. Neste local, as condições de estresse decorrentes das elevadas temperaturas, além de alterarem as condições comportamentais e metabólicas, também podem prejudicar a resposta fisiológica das vacas aos estímulos de ejeção de leite durante a ordenha, uma vez que em situações de estresse, a síntese $\mathrm{e}$ secreção de ocitocina durante a ordenha pode ser prejudicada, e agravar os efeitos negativos do estresse térmico sobre a produção de leite, pois elevadas concentrações plasmáticas de cortisol prejudicam a síntese $\mathrm{e}$ secreção de ocitocina pela hipófise (BRUCKMAIER et al., 1993). Desta forma, disponibilizar condições climáticas adequadas na pré-ordenha pode resultar em aumentos na produção de leite, e conforme resultados do presente estudo, o uso de sombreamento e aspersão pode ser uma alternativa adequada para atingir este objetivo.

O resultado para produção de leite encontrado corrobora com Arcaro Júnior et al. (2003), onde estudaram a ventilação e a aspersão como estratégia de climatização, e encontraram acréscimo de $3,45 \%$ na produção de leite diária em vacas holandesas submetidas a climatização no curral de espera, durante 30 minutos, quando comparadas com as vacas que não receberam climatização no curral de espera.

Estudos (CAMPOS et al., 2002; SILVA et al., 2002; BARBOSA et al., 2004) têm demonstrado que ao serem utilizados artifícios geradores de melhorias das condições ambientais das instalações (ventiladores, nebulizadores, chuveiro em sala de espera), a resposta produtiva dos animais é sempre positiva. Estes resultados ocorrem por que a climatização aumenta a capacidade de perda de calor por meio de evaporação e resfriamento (NÄÄS \& ARCARO JUNIOR. 2001; ARCARO JUNIOR et al., 2003), o que ameniza os efeitos negativos do estresse sobre a síntese e secreção do leite, e também sobre o consumo de alimentos, pois Passini et al. (2009) estudaram os efeitos do estresse térmico (câmara climática $38^{\circ} \mathrm{C}$ ), e relataram redução no consumo e na digestibilidade da matéria seca e dos nutrientes, quando comparado ao consumo dos animais em condições de conforto térmico $\left(21^{\circ} \mathrm{C}\right)$.

Ao analisar os parâmetros de composição do leite na Tabela 2 (proteína, ESD, densidade e gordura) pode-se observar que os mesmos não diferem entre os tratamentos. Estes resultados discordam de Porcionatto et al. (2009), onde o autor descreve aspectos da produção leiteira afetados diretamente pelo estresse térmico. Dentre eles, é descrita a composição do leite como fator determinante a ser alterada pelo estresse calórico, através da redução nos teores de gordura, proteína, cálcio, lactose, ácido cítrico e potássio. No entanto, resultados referentes a composição do leite de vacas em estresse térmico são controversos na literatura. Arcaro Junior et al. (2003), ao avaliarem eficiência da climatização do ambiente da sala de ordenha (ventilação ou ventilação mais aspersão) sobre a composição do leite, não observaram diferenças entre os tratamentos para a variável proteína.

A ausência de efeito da climatização sobre a composição do leite pode ser explicada pelo curto tempo em que os 
animais foram expostos ao sombreamento e a aspersão na sala de espera. Portanto, a climatização na pré-ordenha pode resultar em poucos efeitos, ou até mesmo nenhum efeito, sobre o consumo de alimentos. Consequentemente, o fluxo de nutrientes para a glândula mamária pode não ser alterado pela climatização na préordenha, e desta forma, a síntese dos componentes do leite no lúmen alveolar pode ter sido semelhante entre os tratamentos.

Portanto, a climatização na pré-ordenha pode resultar apenas em melhorias nas condições de conforto das vacas durante a ordenha. Desta forma, a concentração de cortisol plasmático, elevada pelo estresse térmico, pode ser reduzida pela climatização na pré-ordenha. Com menores concentrações plasmáticas de cortisol, a liberação de ocitocina pela hipófise ocorre de forma mais eficiente frente aos estímulos para a produção de leite. Posteriormente, quando a ocitocina chega à glândula mamária em concentrações adequadas para a potencial ejeção de leite, este hormônio se liga aos receptores das células mioepiteliais e estimula a contração muscular, o que resulta em expulsão do leite para os grandes ductos e a cisterna da glândula mamária. Em níveis baixos de ocitocina, como em situações de estresse com elevadas concentrações plasmáticas de cortisol, a ação de ejeção de leite é prejudicada pela reduzida concentração de ocitocina na glândula mamária (BRUCKMAIER et al., 1993), justificando os efeitos negativos do estresse térmico sobre a produção de leite, e os benefícios produtivos da climatização na pré-ordenha.

Os resultados de temperatura retal, freqüência cardíaca, freqüência respiratória e índice de temperatura e umidade mostram que o sistema de climatização adotado foi eficiente para mitigar os efeitos do estresse térmico na pré-ordenha, pois os valores médios destas variáveis foram menores para as vacas que receberam o sistema de climatização, e justificam a maior produção de leite das vacas que receberam a climatização na préordenha (Tabela 3). Alterações nos parâmetros fisiológicos acima citados são justificadas pelo fato da perda de calor por radiação, condução e convecção ser dificultada pelo aumento da temperatura do meio, que quando é elevada ativa os mecanismos de sudorese e aumento da frequência respiratória, ou seja, o centro termorregulador, sediado no hipotálamo, dá início à termólise, especialmente por via evaporativa, através do aumento da freqüência respiratória (McDOELL, 1975).

Tabela 3. Valores médios e erro padrão da média dos parâmetros fisiológicos avaliados nos diferentes tratamentos

\begin{tabular}{lcccc}
\hline \multirow{2}{*}{ Tratamentos } & \multicolumn{4}{c}{ Parâmetros } \\
\cline { 2 - 5 } & $\mathrm{TR}^{\circ} \mathrm{C}^{1}$ & $\mathrm{FC}^{2}$ & $\mathrm{FR}^{3}$ & $\mathrm{ITU}^{4}$ \\
\hline Climatizado & $38,80(0,04)$ & $54,35(0,62)$ & $40,21(0,56)$ & $71,34(1,27)$ \\
Não climatizado & $39,41(0,06)$ & $67,12(0,79)$ & $66,75(0,72)$ & $79,76(1,89)$ \\
CV (\%) & 2,3 & 20,7 & 32,4 & 8,4 \\
$\mathrm{P}$ & 0,033 & 0,019 & 0,028 & 0,001 \\
\hline
\end{tabular}

${ }^{1}$ Temperatura retal em graus Celsius; ${ }^{2}$ Frequência cardíaca (bat./min.); ${ }^{3}$ Frequência respiratória (mov./min.); ${ }^{4}$ Índice de temperatura e umidade. 
A climatização determina a resposta positiva na produção, possivelmente, pela redução na produção de calor endógeno a partir da atividade muscular que é reduzida em situações de ambiente favorável. Pois como observado por Souza et al. (2010) frequência respiratória elevada durante várias horas pode interferir na ingestão de alimentos e ruminação, adicionar calor endógeno a partir da atividade muscular e desviar a energia que poderia ser utilizada em outros processos metabólicos e produtivos. Ainda no estudo acima citado, os autores concluíram que o ambiente físico sombreado apresenta uma redução em mais de $50 \%$ da carga térmica radiante, justificando os efeitos benéficos nos sistemas de climatização que utilizam o sombreamento como uma das estratégias para mitigar os efeitos do estresse térmico.

A frequência cardíaca das vacas que receberam a climatização foi reduzida em 12bat./min., em comparação com as vacas do tratamento controle. Os efeitos do estresse térmico sobre a frequência cardíaca é variável. O aumento ou redução da freqüência cardíaca está na dependência da intensidade de estresse a que os animais estão submetidos, e a capacidade de adaptação dos mesmos. Em intensidade de estresse térmico moderada, a frequência cardíaca é reduzida como resposta a dilatação periférica dos vasos. A diminuição ou manutenção da frequência cardíaca também pode ser observada em animais adaptados ao clima quente. No entanto, vacas em lactação apresentam alta taxa metabólica, e desta forma são sensíveis ao aumento de temperatura acima da zona de conforto térmico, e podem apresentar dificuldades de aclimatação, e resultar em aumento na frequência cardíaca em condições de estresse térmico (KADZERE et al., 2002).
Os valores obtidos de temperatura retal ressaltam o efeito significativo da climatização artificial para mitigar os efeitos do estresse térmico, pois houve redução de $0,6^{\circ} \mathrm{C}$ com a climatização na pré-ordenha em relação às vacas do tratamento sem climatização. Medidas para amenizar o estresse térmico que reduzem a temperatura retal podem ser consideradas eficientes, pois a energia térmica produzida pelas reações metabólicas aquece os tecidos internos a uma temperatura, que pode ser estimada pela temperatura retal, e essa energia passa para a periferia do corpo por condução através dos tecidos e do sangue que irriga a superfície. Ao atingir a epiderme, a energia se reduz e então temos a temperatura da superfície cutânea (Ts). No entanto, conforme já ressaltado, em temperaturas elevadas não ocorre eficientemente perda de calor por radiação, condução e convecção, e desta forma, a temperatura retal é conservada, causando efeitos prejudiciais ao metabolismo e a produção dos animais (SOUZA \& BATISTA, 2012).

Campos et al. (2002) propuseram um limite máximo de 75 , para o índice de temperatura e umidade (ITU), objetivando conforto térmico do rebanho leiteiro da raça Holandesa. Estes autores observaram que valores de ITU de 70 ou menos, não causaram nenhum desconforto térmico para vacas leiteiras. Entretanto, para valores de 75 ou mais, a produção de leite e ingestão de alimentos foi seriamente prejudicada. Estes dados corroboram com os do presente estudo, cujo ITU para as vacas do tratamento climatizado apresentou valor de 71,34, já para as vacas do tratamento sem climatização o valor de ITU foi 79,76, o que resultou em redução na produção de leite como descrito anteriormente. 
Rev. Bras. Saúde Prod. Anim., Salvador, v.14, n.3, p.406-412 jul./set., 2013 http://www.rbspa.ufba.br ISSN 15199940

O sistema de climatização na préordenha pode apresentar benefício na produtividade das vacas devido ao conforto térmico em momento crítico para o animal. Todo o estresse gerado antes da ordenha pode interferir na síntese e secreção de hormônios responsáveis pela produção de leite. Desta forma, amenizar os efeitos do estresse na pré-ordenha é estratégia que demanda baixo custo, baixa mão de obra, e uso reduzido de recursos naturais, e resulta em ganhos significativos na produção (MARTELLO, 2004; SOUZA \& BATISTA, 2012).

Silva et al. (2011) ao estudarem o efeito do resfriamento adiabático evaporativo automático na pré-ordenha, concluíram que este tipo de climatização contribuí para reduzir a temperatura de bulbo seco e a humidade relativa do ar da instalação, resultando em menor frequência respiratória, temperatura corporal, temperatura retal, índice de temperatura e úmida dos animais, e aumento de $3,66 \%$ na produção de leite, recomendando 40 minutos de permanência dos animais neste tipo de ambiente climatizado.

Verificou-se que o acondicionamento das vacas a sombreamento e aspersão na pré-ordenha durante 30 minutos, resulta em menor temperatura retal, frequência cardíaca, frequência respiratória, e aumento de $12,4 \%$ na produção de leite, onde se conclui que a estratégia de climatização adotada para mitigar os efeitos do estresse térmico sobre as vacas em lactação, pode contribuir com ganhos econômicos na produção leiteira, devido ao baixo custo e a facilidade de adaptar este sistema em diferentes condições de manejo dos animais.

\section{REFERÊNCIAS}

ASSOCIATION OF OFFICIAL ANALYTICAL CHEMISTS - AOAC. Official methods of analysis. $16^{\text {th }} \mathrm{ed}$. Arlington, 1995.

ARCARO JUNIOR, I.; ARCARO, J.R.P.; POZZI, C.R.; FAGUNDES, H.; MATARAZZO, S.V.; OLIVEIRA, C.A. Teores plasmáticos de hormônios, produção e composição do leite em sala de espera climatizada. Revista

Brasileira de Engenharia Agrícola e Ambiental, v.7, n.2, p.350-354, 2003.

AVENDANO, R.L.; ALVAREZ, V.F.D.; CORREA, C.A.; SAUCEDO, Q.J.S.; ROBINSON, P.H.; FADEL, J.G. Effect of cooling Holstein cows during the dry period on posíparíum performance under heat stress conditions. Livestock Production Science, v.105, p.198-206, 2006.

BARBOSA, O.R.; BOZA, P.R.; SANTOS, G.T.; SAKAGUSHI, E.S.; RIBAS, N.P. Efeitos da sombra e da aspersão de água na produção de leite de vacas da raça Holandesa durante o verão. Acta Scientiarum Animal Science, v.26, n.1, p.115-122, 2004.

BUFFINGTON, D.E.; COLLIER, R.J.; CANTON, G.H. Shede managemente systems to reduce heat stress for dairy cows. St. Joseph: American Society of Agricultural Engineers, 1982. 16p.(Paper 82-4061).

BRUCKMAIER, R.M.; SCHAMS, K.; BLUM, J.W. Milk removal in familiar and unfamiliar surroundings: concentrations of oxytocin; prolactin; cortisol and $\beta$-endorphin. Journal of Dairy Research, v.60, n.4, p.449-456, 1993. 
Rev. Bras. Saúde Prod. Anim., Salvador, v.14, n.3, p.406-412 jul./set., 2013 http://www.rbspa.ufba.br ISSN 15199940

CAMPOS, A.T.; KLOSOWSKI, E.S.; GASPARINO, E.; CAMPOS, A.T.

Estudo do potencial de redução da temperatura do ar por meio do sistema de resfriamento adiabático evaporativo na região de Maringá-PR. Acta

Scientiarum Animal Science, v.24, n.5, p.1575-1581, 2002.

DIKMEN, S.; HANSEN, P. J. Is the temperature-humidity index the best indicator of heat stress in lactating dairy cows in a subtropical environment?

Journal of Dairy Science, v.92, p.109$116,2009$.

KADZEREA, C. T.; MURPHYA, M. R.; SILANIKOVEB, N.; MALTZB, E. Heat stress in lactating dairy cows: a review. Livestock Production Science, v.77, p.59-91, 2002.

MARTELLO, L.S.; SAVASTANO Jr.; H.; SILVA, S.L.; TITTO, E.A.L.

Respostas fisiológicas e produtivas de vacas holandesas em lactação submetidas a diferentes ambientes. Revista

Brasileira de Zootecnia, v.33, n.1, p.311, 2004.

McDOWELL, R. E. Bases biológicas de la producción animal en zonas tropicales. Zaragoza: Acríbia, 1975. 692p.

NÄÄS, I.A.; ARCARO JUNIOR, I. Influência de ventilação e aspersão em sistemas de sombreamento artificial para vacas em lactação em condições de calor.

Revista Brasileira de Engenharia Agrícola e Ambiental, v.5, n.1, p.139142, 2001.

PASSIN, R.; FERREIRA, F.A.; BORGATTI, L.M.O.; TERÊNCIO, P.H.; SOUZA, T.Y.B.S.; RODRIGUES, P.H.M. Estresse térmico sobre a seleção da dieta por bovinos. Acta Scientiarum. Animal Sciences, v.31, n.3, p.303-309, 2009.
PORCIONATTO, M.A.F.; FERNANDES, A.M.; NETTO, A.S.; SANTOS, M.V. Influência do estresse calórico na produção e qualidade do leite. Revista Acadêmica Ciências Agrárias e Ambientais, v.7, n.4, p.483-490, 2009.

SAS Institute. SAS user's guide: statiscs. Version 8.2. Cary, 2001. 1028p.

SILVA, I.J.O.; PANDORFI, H.; ACARARO JUNIOR, I.; PIEDADE, S.M.S.; MOURA, D.J. Efeitos da Climatização do Curral de Espera na Produção de Leite de Vacas Holandesas. Revista Brasileira de Zootecnia, v.31, n.5, p.2036-2042, 2002.

SILVA, I.M.; PANDORFI, H.; GLEDSON L.P.; ALMEIDA, C.G.; HUGO, M.H. Benefits of automated acclimatization during the pre-milking phase of lactating girolando cows. Engenharia Agrícola, v.31, n.5, p.847856, 2011.

SOUZA, B.B.; MELLACE, E.M.; SANTOS, R.F.S.; ZOTTI, C.A.; GARCIA, P.R. Avaliação do ambiente físico promovido pelo sombreamento sobre o processo termorregulatório em novilhas leiteiras. Agropecuária Científica no Semiárido, v.6, n.2, p.5965, 2010.

SOUZA, B.B.; BATISTA, N.L. Os efeitos do estresse térmico sobre a fisiologia animal. Agropecuária Científica no Semi-Árido, v.8, n.3, p.0610, 2012.

WEST, J.W. Effects of heat stress on production in dairy cattle. Journal Dairy Science, v.86, n.6, p.2131-2144, 2003.

Data de recebimento: 16/04/2013

Data de aprovação: 26/06/2013 